\title{
THE HAZARDS OF PAINTING AND VARNISHING 1965
}

\author{
BY \\ ROBERT PIPER \\ From Imperial Chemical Industries Ltd., Paints Division, Slough, Bucks.
}

(RECEIVED FOR PUBLICATION JULY 29, 1965)

\begin{abstract}
A review of paint hazards is made, giving brief descriptions of methods of application in use in 1965 , of paint usage according to resin base, and of paint ingredients. The most interesting and complex of these are the resin bases, which have much in common with plastics.

Reference is made to some of the many minor ingredients. The problem of keeping abreast of the possible toxic effects, so that paint manufacturers and their customers may be warned and protected, will be clear.
\end{abstract}

The application of paint or varnish to a surface is a problem common to nearly every industry and home in the country. Shipping, aircraft, and motorcars, domestic and electrical equipment, buildings, any surface, in fact, which needs protection or decoration will need a surface coating. Different formulations are used to produce the necessary properties, such as weather or chemical resistance, inhibition of the growth of algae or barnacles, electrical insulation or lowered friction effects of the air at high speed.

In spite of the number of people involved and the scattering of painters in relatively small numbers in industry everywhere, and the wide variety of situations and formulations in which paint is applied, very few cases of harm are reported from fire, contact or poisoning.

Because of the continual introduction of new materials, new processes, and new methods of application there is a need for regular and systematic checking of evidence to seek out any hazards in new materials or existing formulations that may endanger humans, animals or plants.

\section{Definition}

A paint is defined as a liquid containing a suspended pigment applied to adhere to a solid surface and to protect and decorate it. Without pigment a clear film is usually called a varnish. A paint drying by evaporation, often cellulose-based, is a lacquer (with or without pigments). The term 'enamel' is applied to good quality, hard gloss paints, comparing them to the hard durable enamel on baths. The term 'synthetic enamel' is also used, meaning an enamel paint based on synthetic resins.

Paints ordinarily consist of powdered solids (pigments) suspended or dispersed in a liquid vehicle. Most of these vehicles are composed of resins with sufficient solvents added to create the consistency best suited to the means of application. The consistency varies according to usage, e.g., brushing, spraying or dipping. The varnish, or vehicle, is chemically very variable, and the branch of paint technology concerning vehicles is closely allied to that of plastics, having in common the building up of chains or nets of molecules or of solid macromolecules to form stable coherent materials producing toughness, hardness, and other qualities needed. Formations of these polymers may be from a single type of molecule or monomer or from two or more different types of molecule, copolymers or heteropolymers. The chemistry is involved, but a number of main types of resin are used in paints, e.g., alkyds and acrylics, and these will be referred to later.

\section{Methods of Application}

Until the 1920s the common method of painting was by brushing. Today, a variety of methods are in use.

Brushing.-Brushing by a hog's bristle or nylon brush is widely used for shipping, house decoration, and for small repainting tasks. Roller painting, using a lambswool or nylon roller, simplifies the brushing 
technique and, as domestic painters know, increases speed of application to large flat areas.

Dipping.-This is used widely in industrial manufacture. Hand dipping is used for small objects, but dip tanks with mechanical devices for lowering and raising the objects are the rule. Withdrawal at controlled speed is important.

Roller Coating, Reversed Roller Coating, Curtain Coating, and Veil Coating.-In these methods flat surfaces are coated mechanically with a film of paint applied in a line across the object. Exact film thickness, evenness of application, and little loss of paint are advantages, but the methods are limited to flat sheets of metal or wood which pass readily under the rolls.

Flow Coating. - A thinner paint with a higher boiling solvent is used.

Paint Spraying.-This can be carried out by hand or automatically. It can be done by the use of air under pressure which is driven across the mouth of a small paint outlet in the gun to produce an air/paint mist. In hot spraying the viscosity of the paint is reduced by the application of heat so that less solvent is required and thicker films can be applied. Airless spraying uses pressure applied directly to the paint to force it through a jet and break it up into fine droplets.

Electrostatic Spraying.-This is carried out by applying electrostatic charges to the spray gun, the object to be painted being earthed. The sprayed paint droplets take up the charge from the gun and are attracted to the object, penetrating crevices and even swinging round to the back of the object. Less paint is lost over the object (overspray) and more complete cover is given. It is used mainly for small objects. Voltages up to $100 \mathrm{kV}$ are used, but hand guns are designed so that the head can be touched safely by hand, because of the low current. Automatic electrostatic spraying behind guards may carry a current of as much as $10 \mathrm{~mA}$, which would be immediately lethal if touched.

Electrocoating.-This is not comparable to the above. Voltages of under $200 \mathrm{~V}$ are used with a high current: 1,000 to $5,000 \mathrm{amp}$. with $50 \mathrm{~V}$ or $60 \mathrm{~V}$ on an open busbar are accepted as safe, the voltage being insufficient to allow the current to overcome bodily resistance. This type of coating is waterbased, and consequently little fire hazard exists. This novelty in industrial painting is a highly desirable property to managements. For example, motor-car bodies can be moved along a charged conveyor belt and dipped into a tank of paint. Deposition of paint is, in some way, comparable to metal deposition in electroplating.

\section{Comment}

The major hazards of painting are fire and gassing. Both are so well known that little comment is needed, but this much is to be said. The introduction of water-based paints by electrocoating and other methods is revolutionary and removes the fire hazard from industrial painting; at present still in the development stage, their use may be extended. The risk of gassing from solvents is greatest where painting takes place in an enclosed space and where facilities for evaporation are increased, as in spraying paint or by hot processing of paints. The last is normally cared for by plant design, and this hazard should never arise. In spite of the obvious character of the danger, risks in brush and spray painting are taken and, although unconsciousness or worse is seldom reported, minor symptoms are common. Brush painting inside tanks and small rooms without the use of protective devices or special ventilation is one fault. Spraying of paint without exhaust ventilation and without respirators is also common. Where protection is provided, it is often not used or not used properly. Objects to be painted are sprayed outside spray-booths, sometimes even by the painter standing inside the booth. The correct respirator for the task is seldom seen and even less often used, the only type seen at all commonly being the simple gauze mask which stops no solvent vapour at all. It is hardly surprising therefore that complaints about irritant vapours are frequent when formulations are changed and an unfamiliar solvent is introduced. Solvent naphtha, butanol, and methyl isobutyl ketone (M.I.B.K.) are all of this type, producing vapours which irritate the eyes and nose but carrying no serious danger. Once the subject is accustomed to the minor irritations of these, no further complaints occur. With airless spraying the inhalational hazard is reduced.

\section{Raw Materials}

In the making of paints raw materials are often reacted so that they undergo chemical change and lose their original properties. In other cases they are unchanged or residues remain. For this reason, it is as well to know something of these raw materials so that judgement may be made of the potential hazards of the finished paint or varnish.

For convenience, the raw materials will be 
described in this order: resins; solvents; pigments; and minor ingredients, including fungicides.

Resins.-The resins used in paints will be described as follows: (1) alkyd resins, oleoresins; (2) urea melamine and phenol formaldehyde condensate resins; (3) polyester derivatives; (4) cellulose; (5) acrylic resins; (6) epoxy resins; and (7) polyurethane resins.

Alkyd Resins.-Alkyd resins are condensed from polycarboxylic acids and polyalcohols. Often the anhydride of phthalic acid and glycerol or pentaerythritol are used, viz.:
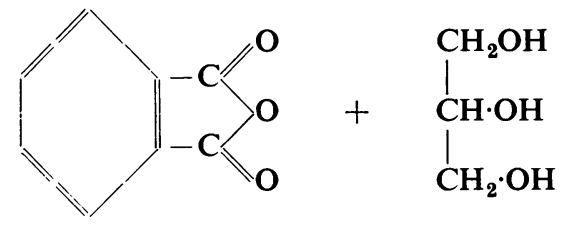

Phthalic anhydride

Glycerol

A fatty acid is often used to modify the resin by combination with the $-\mathrm{C}-$ atom marked (1). Plasticizers may be added, including other resins based on adipic or sebacic acid.

There are no major hazards from this group of resins. The ingredients are mainly reacted in manufacture, and none of the potentially noxious basic raw materials is likely to remain free. For example, phthalic anhydride fume, a known bronchial irritant, disappears as such in manufacture. Alkyd resins have a long and broad history, and the experience of many years makes the chance of new information of chronic toxic hazards from their use unlikely.

Formaldehyde Based Resins (including Nitrogen Resins)._Large numbers of long established resins are based on the reaction of formaldehyde or paraformaldehyde with phenol or urea. Occasionally another aldehyde is used in place of formaldehyde, melamine in place of urea, and higher phenols in place of phenol itself. These resins are frequently used to modify others. They are used mainly in paint vehicles, and in the finished state are not known to cause systemic poisoning. Traces of formaldehyde may be present occasionally, sufficient to smell in some of the resins; rarely is it a cause of trouble. Zielhuis (1961) quotes a case of asthma 'probably due to emanating formaldehyde' in the acid curing of urea-formaldehyde based paint. As might be expected, occasional skin irritation is known to occur.

Polyester Resins.-Polyesters are formed by the reaction of a polybasic acid and a polyhydric alcohol to form a series of ester finishes (Lawrence, 1960).

The so-called 'polyester' finishes introduced about

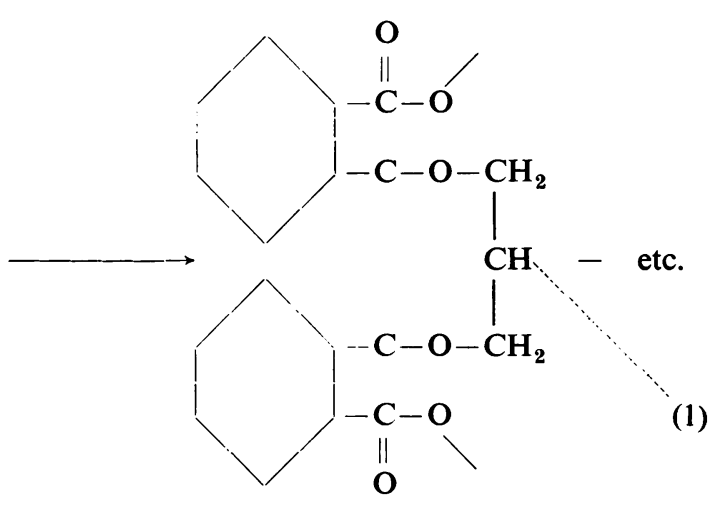

Alkyd resin unit

ten years ago are carried in styrene or other reactive monomers, which not only act as the solvent, but cross-link with the polyester resin to form a thick tough film. The 'curing' or cross-linking reaction is triggered off by the addition of an organic peroxide immediately before application.

These solutions of organic peroxides may themselves be corrosive.

They are not oil modified. Confusion arises, however, as the term 'polyester resin' is sometimes used to indicate the dry film.

In general, the only hazard from present-day polyester finishes could be the hazard of the crosslinking agents. It is possible that these (other than styrene) will be used in the future, and hazards may be introduced in them, since residues may remain in some cases unreacted. Such cross-linking agents already under investigation are vinyl toluene and allyl compounds, some of which have well-known toxic properties.

Styrene, or vinyl benzene $\left(\mathrm{C}_{6} \mathrm{H}_{5} \cdot \mathrm{CH}: \mathrm{CH}_{2}\right)$ is not a serious hazard, partly because its smell and power 
to irritate the eyes and mucous membrane make it obnoxious below harmful levels.

INDUSTRIAL EFFECTS.-In man, the smell of styrene is stated to be detectable at varying concentrations, the lowest estimate being 'below 10 p.p.m.' (Wolf, Rowe, McCollister, Hollingsworth, and Oyen, 1956). Irritation effects become immediately unpleasant above 600 p.p.m. but the smell is very disagreeable at 200 to 400 p.p.m. (Spencer, Irish, Adams, and Rowe, 1942). No systemic effects on the blood, liver, kidneys or central nervous system have been observed in animals or man. All symptoms reported have been attributable to minor narcotic effects (drowsiness, lassitude) or irritative. The M.A.C. recommended by the American Conference of Governmental Industrial Hygienists in 1964 was 100 p.p.m. based on the irritative properties. Dutch workers have recommended a lower M.A.C. (50 to 70 p.p.m.) to exclude these lighter symptoms (Malten and Zielhuis, 1964). Russian workers use an M.A.C. of 12.5 p.p.m., and Pokrovski (1961) recommended an even lower level based on work in women workers when a disturbance of higher nervous activities and gynaecological disorders were found.

Cellulose Paints and Lacquers.-These paints are based on solutions of nitrocellulose (i.e., cellulose nitrate) and of cellulose acetate, etc. in mixed solvents. They were first used because they dry quickly, the speed being controlled by variations of the solvents' formulation which makes them especially suitable for spraying. They are used today in aircraft dopes and lacquers on motor-cars, as wood finishes, for paper coating (glossy paper), and in the manufacture of leathercloth, cinema film, and cellophane.

1. Solvents most commonly used in wood lacquers in Great Britain were listed in Non-Convertible Coatings 1961 as 32 in number. They include esters, ketones, complex ethers, alcohols, and hydrocarbons. In general, they are free from any noxious effects. Benzene may be present as an impurity in toluols. The general hazard of all is that of gassing, should vapour concentrations rise too high.

2. Plasticizers include castor oil, dibutyl phthalate, tributyl phosphate, tricresyl (tritolyl) phosphate, dioctyl phthalate, and others, and may be present in quite high concentration. Of them, tricresyl (tritolyl) phosphate is well known as a neurotoxic agent.

3. Nitrocellulose and resins: the resins used today include natural resins or ester gums, non-drying oil modified alkyds, hard maleic-based resins, and styrenated alkyds, etc. None has any special toxic hazard.

4. Solids: lead pigments are rarely used in cellulose paints. Regulations virtually prohibit their use above the $5 \%$ 'soluble' lead level.

ToxicITY.-In general, the hazard of cellulose lacquer has always been of fire rather than toxicity. The toxic hazards of cellulose paints may be briefly summarized thus:

1. Solvents:

(a) Benzene, seldom used as such, possibly present as impurity

(b) Tetrachlorethane, now only used abroad in an allied industry

(c) All others, gassing hazard easily controlled by ventilation.

2. Plasticizers: Tricresyl (tritolyl) phosphate is the only known hazard and is reduced by using only meta and para isomers. In any case a percentage up to $4 \%$ is the maximum in liquid paint.

3. Nitrocellulose and resins: No toxic hazard known.

4. Pigments: Similar to other paints but low lead hazard.

Acrylic Resins.-Acrylic resins are based on one or other of a series of related compounds:

Acrylic acid, $\mathrm{CH}_{2}: \mathrm{CH} \cdot \mathrm{COOH}$, or acrylates

Methacrylic acid, $\mathrm{CH}_{2}: \mathrm{C}\left(\mathrm{CH}_{3}\right) \cdot \mathrm{COOR}$, or methacrylates

Acrylonitrile $\mathrm{CH}_{2}: \mathrm{CH} \cdot \mathrm{CN}$

Acrylamide $\mathrm{CH}_{2}: \mathrm{CH} \cdot \mathrm{CO} \cdot \mathrm{NH}_{2}$

As the groups ' $R_{1}$ ', $\left(\mathrm{COOR}_{2}\right)$ in the acrylate formula $\mathrm{CH}_{2}: C{ }_{\mathrm{COO} \mathrm{R}_{2}}^{\mathrm{R}_{1}}$ may be reactive and the

double bond between the two $\mathrm{C}$ atoms allows for ready polymerization, a wide variety of useful compounds may be made; one company alone listed 161 acrylic monomers in its catalogue in 1960.

In practice, the double bond is only one of the possible reactive groups, the others being a carboxyl, nitrile, amide or glycidyl group in the end position $\left(\mathrm{COOR}_{2}\right)$.

Polymerization of acrylates in solution or in heterogeneous systems may be used in paints. In solution methods, organic solvents such as esters, acetone, and toluene are used, and a catalyst is added. The catalysts are often organic peroxides. The heterogeneous system is used in preparing vehicles for emulsion paints, i.e., water-based typesgenerally vinyl acetate/acrylics or acrylic copolymers. In addition, there may be a wetting agent, a preservative, antifoaming agent, corrosion inhibitor, levelling agent, and pigments, filters, and thickeners. Of the minor ingredients, preservatives may include sodium pentachlorphenate. 
The hazard from the monomers is eliminated by completing their reaction into the resin system. The objectionable persistent and irritant smell of acrylate monomers and of methacrylate monomers is only a rough guide to the efficiency of completion. The smells of methyl and ethyl acrylates are perceptible above 81 and 25 p.p.m. respectively (Maglio, 1948), whereas the M.A.C. values accepted at present as desirable are set at 10 p.p.m. and 25 p.p.m.

Treon, Sigmon, Wright, and Kitzmiller (1949) showed that the inhalation of 31 p.p.m. for 185 days or 95 p.p.m. for 70 days was well tolerated by rabbits, guinea-pigs, rats, and monkeys, whereas 200 p.p.m. was lethal.

Methacrylates are generally less dangerous than acrylates, and in both groups the higher esters are less dangerous than the lower.

The monomers of acrylamide and acrylonitrile both carry moderately severe hazards, the first being a powder which creates little dust. In the manufacture of resins, tests were carried out while loading by hand, and these failed to show detectable quantities of acrylamide in the atmosphere around the loading point. This is explained by the physical nature of the powder, which appears to be almost self-adhesive. The chief hazard is its ability to be absorbed through the intact skin, as manufacturers point out. When processed into resin, it should not be present in detectable quantities.

Acrylonitrile is the most dangerous raw material in the group and can cause cyanide-like effects which are well known. Chronic acrylonitrile effects occur with quite low concentrations. In dogs, 60 p.p.m caused serious intoxication in four weeks. Polyacrylonitrile dust caused lung trouble in rabbits after intratracheal ingestion (Massmann, 1956). Lomonova (1962) reported kidney and liver degeneration in rats. This dosage was hardly related to industrial exposure. However, acrylonitrile used for disinfecting dormitories poisoned several persons and its inhalation caused the death of a 3-year-old girl (Grumske, 1949). It also caused the death of a 10-year-old girl, whose mother used it to treat the daughter's scalp (Lorz, 1950).

Epoxy Resins.-Epoxy resins were introduced as an improvement on existing materials because of their chemical resistance and heat stability. To quote Skeist (1958): 'Epoxy-melamine resins are found superior or equal to others in alkali resistance, acid resistance, hardness, flexibility, staining and weather durability. Their adhesion to metals is outstanding, their resistance to high temperature surpassed only by silicones.' They are applied to washing machines, acid electroplating tanks, drum-linings, laboratory furniture, and as motor-car primers. Solutions of epoxide intermediates are employed, usually modified with urea-formaldehyde, phenol-formaldehyde or melamine-formaldehyde resins or reacted with fatty acids to give epoxy esters. They are used in potting compounds, for the embedding of transistorized equipment, and for other purposes in plastics and paints.

CHEMISTRY.- The epoxy group (Ep) is- $\mathrm{HC} \triangle \mathrm{CH}_{2}$. It has one free bond but can easily free two more. A diepoxide (or bisepoxide) is easily formed by the attachment of two epoxy groups to a polyhydroxy compound, e.g., R.(OH) $)_{2}$, by reaction with epichlor-

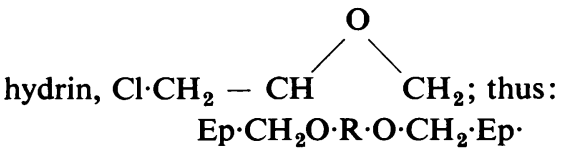

which is a diglycidyl ether, the $\mathrm{R}$ being variable. The two Ep groups can now be further condensed to form an epoxy resin, say, with diphenylol propane ['bisphenol A' (2.2 bis (p. hydroxyphenyl) propane, $\left.\mathrm{C} \cdot\left(\mathrm{CH}_{3}\right)_{2} \cdot\left(\mathrm{C}_{6} \mathrm{H}_{4} \cdot \mathrm{OH}\right)_{2}\right)$ ], thus:

$\mathrm{Ep} \cdot \mathrm{CH}_{2}\left(\mathrm{OC}_{6} \mathrm{H}_{4} \mathrm{C}\left(\mathrm{CH}_{3}\right)_{2} \cdot \mathrm{C}_{6} \mathrm{H}_{4} \cdot \mathrm{O} \cdot \mathrm{CH}_{2} \cdot \mathrm{CHOH} \cdot \mathrm{CH}_{2}\right)_{\mathrm{n}}$ $\cdot \mathrm{O} \cdot \mathrm{C}_{6} \mathrm{H}_{4} \cdot \mathrm{C}\left(\mathrm{CH}_{3}\right)_{2} \mathrm{C}_{6} \mathrm{H}_{4} \cdot \mathrm{O} \cdot \mathrm{CH}_{2} \cdot \mathrm{Ep}$.

The $\mathrm{n}$ can be carried upwards from zero to form different compounds. Each of the two epoxy groups has still two bonds to link on-<smiles>[R1]C(C)COC</smiles>

so that a diepoxide has four possible linkages and is ideal for cross-linking in the formation of nets or box molecules in polymerization.

There are many epoxy resins sold today under trade names, e.g., Araldite, Epon, Epikote, each name specifying the manufacturer. A number following the trade name signifies the exact resin.

These epoxy resins are also used in two-pack systems, a curing agent being needed to complete the formation of the finish. A variety of curing agents (hardeners) are used, but in coating solutions the more agressive (to the skin) organic amines are less used, and the polyamides have replaced them to a great extent. Other curing agents include acidic materials.

EXPERIMENTAL.- In 1951, soon after the introduction of these materials, Hendry, Horner, Rose, and Walpole (1951) found carcinogenic properties in some of them. This work has been amply confirmed since (Hine, Kodama, Anderson, Simonson, and Wellington, 1958; Walpole and Williams, 1959; Kodama, Guzman, Dunlap, Loquvam, Lima, and 
Hine, 1961). However, Walpole and Williams (1959) were able to show that epoxy resins based on diphenylol propane and diglycidyl ether did not possess these carcinogenic properties. Today there are many epoxy resins on the market mostly based on diphenylol propane. There are, however, other epoxy resins not at present used in surface coatings, which are known to be carcinogenic. In most cases resin manufacturers specify the hazard in their technical hand-outs. As it is theoretically possible to epoxidize almost any chemical, the range of chemical possibilities is vast.

So far, the hazard of carcinogenicity appears to be restricted to certain molecular weight liquid epoxy resins. This means that present-day epoxy resin coatings are free from this risk.

Polyurethane Resins.-The isocyanate radical $-\mathrm{N}: \mathrm{C}: \mathrm{O}$ is extremely reactive chemically. Some compounds containing two isocyanate groups have the property of polymerizing into materials useful in the fields of foam rubbers and lacquers. Thus:

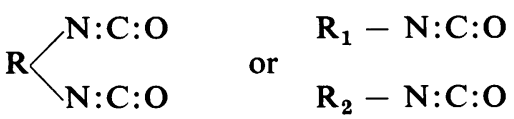

may combine with a polyol (polyhydric alcohol) (A)

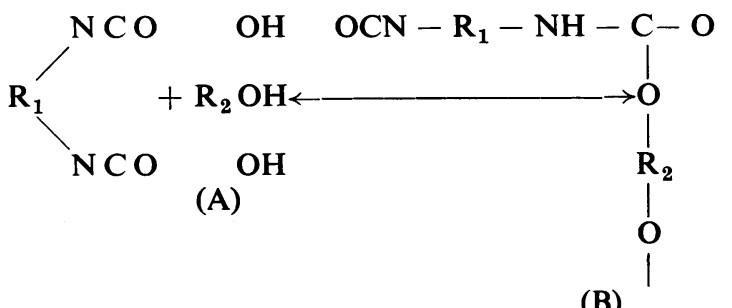

to produce a polyurethane (B).

In the lacquer field, most of these products are made up in two-pack systems, one containing the polyisocyanate activator. The material to be activated may be a polyester resin or polyether.

Originally two di-isocyanates were introduced, tolylene di-isocyanate (T.D.I.) and hexamethylene di-isocyanate (H.M.D.I.). Both these materials are comparatively volatile, and cases of bronchospasm were reported. They are now considered too toxic for ordinary use in lacquers. Today, however, chemists have evolved polyisocyanates, which have much lower vapour pressure, and the active isocyanate groups are masked so that the M.A.C. of 0.02 p.p.m. is not exceeded even on spraying finishes.

EXPERIMENTAL.-Friebel and Lüchtrath (1955) introduced $0.3 \mathrm{ml}$. T.D.I. into the trachea of guinea- pigs, which died with respiratory distress. Exposures of guinea-pigs to an aerosol of $1,200 \mathrm{mg}$./ $\mathrm{M}^{3}$ or to a vapour of 350 to $550 \mathrm{mg}$./ $/ \mathrm{M}^{3}$ during irregular 10 - to 20-minute periods over a month produced asthmalike attacks after the first few inhalations. Symptoms worsened with later inhalations.

Zapp (1957) exposed rats to 600 p.p.m. vapour T.D.I. $\left(4,200 \mathrm{mg} . / \mathrm{M}^{3}\right)$ for six hours with lethal results, whereas exposure to 60 p.p.m. resulted in no deaths. He carried out a series of tests on various animals to produce minimal respiratory symptoms followed occasionally by bronchitis or pneumonia but not by asthma-like attacks. He used 1 to 2 p.p.m. T.D.I. ( 7 to $14 \mathrm{mg} . / \mathrm{M}^{3}$ ) for $30 \mathrm{~min}$. to six hours on rats, rabbits, guinea-pigs, and dogs. Henschler, Assmann, and Meyer (1962) failed to produce any pathology with 0.1 p.p.m., but their rats and guinea-pigs failed to gain weight. Duncan, Scheel, Fairchild, Killens, and Graham (1962) measured the 14-day LD $_{50}$ thus: rats 13.9 p.p.m., guinea-pigs 12.7 p.p.m., rabbits 11 p.p.m., mice 9.7 p.p.m. All these used T.D.I. In addition, naphthylene di-isocyanate was tested endotracheally and produced obliterating bronchiolitis in rabbits (Klavis and Schulz, 1959).

Ehrlicher and Pilz (1956) exposed human volunteers for one minute to T.D.I. vapour. They detected its smell first at a concentration of 0.138 p.p.m. and some irritation at 1.9 p.p.m. Other observers found the levels of smell detection to bee 0.4 p.p.m. (Strayer, 1959), 0.1 to 0.2 p.p.m. (Munn, 1960), and 0.05 p.p.m. (Henschler et al., 1962). It is clear that the odour threshold is not a useful guide to danger, as in all cases it was found to be well above the M.A.C. of 0.02 p.p.m. and because in paint application it will be partly masked by the smell of solvents (Malten and Zielhuis, 1964).

INDUSTRIAL EXPERIENCE.-Earlier experiences with isocyanates suggested that they caused lacrimation, respiratory irritation and sensitization, and skin sensitization. From 1951 (Fuchs and Valade) to 1959 (Bosshard) cases or groups of cases were reported in Germany, France, the United States, and Sweden. The Chief Inspector of Factories, in his Annual Reports for 1956 and 1958, referred to their toxicity. In all these reports, T.D.I. or hexamethylene diisocyanate were the accused chemicals. Up to 1959 there were reports of cases among those using twocomponent polyurethane lacquers. Among these were deaths in an asthmatic state (Schürmann, 1955). Swensson, Holmquist, and Lundgren (1955) and Bosshard (1959) recorded a series of cases, Bosshard's 81 cases including $93 \%$ with dyspnoea and $80 \%$ with tracheitis or asthmatic bronchitis. None of these cases was severe. All cleared within three weeks. 
Since 1959 no cases have been reported in the use of paints; this is undoubtedly due to the replacement of T.D.I. by much less hazardous substances derived from isocyanates, such as Desmodur L or Suprasec 3240.

Symptoms reported from the use of isocyanatebased lacquers have been almost entirely respiratory. Characteristically febrile asthma-like attacks occur. Occasionally a marked sensitivity to re-exposure develops. The lesser cases of cough and dyspnoea do not develop into the more severe asthma-like condition. This syndrome is not to be expected from isocyanates today, but vigilance in the introduction of new types is mandatory. Lesser cases may still be expected to be reported, which will be indistinguishable from similar symptoms caused by solvent vapours and result from the poor preventive hygiene so commonly practised by painters, partly from inadequate facilities, but as often from a lack of interest on the part of the painter. Spray booths are useless unless used efficiently; respirators must be properly fitted and maintained.

Droplets of isocyanates may cause cough and tracheal irritation if inhaled in quantity, but these effects can be prevented by the use of face shields. Similarly, conjunctival irritation is to be expected from splashing during paint spraying. Dermatitis is not likely to be caused by isocyanates.

The classification of paints is complex. The use of different types of paints generally follows this pattern and is clearly based on the resins in the vehicle:

\section{Decorative \\ Topcoats \\ Gloss \\ Eggshell \\ Flat}

Undercoats

Primers

Emulsion

paints

Alkyd based or oleoresinous

Alkyd based or oleoresinous

Alkyd based or oleoresinous

Alkyd based or oleoresinous

Oleoresinous or less often alkyd based (white lead/ linseed oil or boiled oil primers are also used; they carry a label 'Contains Lead'.)

Water based

2. Industrial Finishes:

These are applied to a wide range of manufactured goods. They may be (1) air drying at ambient temperatures, or (2) stoving finishes. Most types of base are used according to need.
3. Car Finishes and Refinishes:

Alkyd-Melamine formaldehyde.

Acrylic lacquers and modified thermosetting acrylics.

Nitrocellulose finishes.

\section{Aircraft:}

A wide variety of finishes. Most modern are the epoxy and polyurethane finishes.

5. Marine:

1. Above water-similar to decorative.

2. Below water-a wide range including bituminous paints. Ingredients are included to prevent underwater plant growth and barnacles.

6. Wire Enamels:

Polyester resins ('potting' compounds similar).

Polymer solutions.

7. Wood Finishes:

Nitrocellulose-alkyd blend.

Acid catalysed-amino resin (melamine or urea formaldehyde)-oil modified alkyd blend.

Polyester resins.

Polyurethane resins.

Solvents.-Paint solvents are commonly called 'thinners' and fall into three main categories, each associated with a group of paints.

Hydrocarbons are used in most types of paints including decorative finishes and lacquers, in cellulose and vinyl copolymer finishes, as well as a variety of compounds, esters, alcohols, and ketones. Hydrocarbons are not nitrocellulose solvents. Other ingredients may be added for such reasons as drying times.

Water is the main solvent for distempers, emulsion paints, and electrocoat finishes.

Chlorinated solvents have been used as paint strippers and have recently been introduced in dip painting, and an extension to spray painting is developing.

In general, all solvents can cause gassing. The chance of a man's being gassed depends as much on his environment at work as on the solvent. An enclosed space, such as a tank, man-hole or small room with poor ventilation aggravated by a high surrounding temperature, gives the greatest opportunity for a disaster. Atomization and high vapour concentrations are more likely when spray painting. 
Lesser symptoms such as faintness, headache, visual disturbance, nausea, anorexia, weakness, and general malaise may all arise, and occasionally vomiting and prostration. These conditions occur even with brush painting under poor conditions of ventilation and are the result of inhaling high concentrations of solvent vapours.

Hydrocarbon Solvents.-These are chemically divided into aromatic and aliphatic groups. It is more useful here to group them as benzene and others. Benzene is the most dangerous solvent in use in industry today; other hydrocarbons carry only the general hazards of solvents with minor reservations.

BENZENE (aromatic benzene $\mathrm{C}_{6} \mathrm{H}_{6}$ ) (B.P. $80^{\circ} \mathrm{C}$.). This needs clearly distinguishing from benzine (petroleum benzine), which is aliphatic and undistinguished among the petroleum products. Aromatic benzene is seldom used in surface coating today but will be found if a customer specifies it and as an impurity in commercial toluols, especially toluol 90s. Benzene is known to cause blood dyscrasias.

WhITE SPIRIT (turpentine substitute) (B.R. $150^{\circ}$ to $190^{\circ} \mathrm{C}$.).- This is a petroleum distillate distinguished by having a boiling range similar to that of turpentine. It is not a cause of chronic systemic industrial poisoning. A skin defatting agent, it may cause irritation if used as a skin cleanser but is rarely a sensitizing agent. Its constitution varies chemically according to the source of the petroleum from which it is distilled, but it contains no benzene.

Toluol (toluene) (B.R. $109^{\circ}$ to $111^{\circ} \mathrm{C}$.).-This also is not a cause of any chronic systemic industrial poisoning. Cases were described prior to 1940 but were usually attributed to mixtures of toluol of unknown origin or specification. von Oettingen, Neal, Donahue, Svirbely, Baernstein, Monaco, Valder, and Mitchell (1942) did not regard it as an industrial problem. Acute gassing will occur if high vapour concentrations are allowed to arise, and lesser symptoms at borderline concentrations. Toluol 90 and other grades contain varying amounts, rising to as much as $20 \%$ aromatic benzene. An allowance for benzene effects must be made.

XYLoL (commercial grades of xylenes) (B.R. $135^{\circ}$ to $145^{\circ} \mathrm{C}$.).-This contains no benzene; it is excluded by the boiling point. No chronic systemic industrial effects are likely to occur. The hot vapours are irritating to the eyes and mucous membranes but not unusually dangerous.

TURPENTINe $\left(\mathrm{C}_{10} \mathrm{H}_{16}\right)$ (B.R. $155^{\circ}$ to $180^{\circ} \mathrm{C}$.).-This is an extract of pine trees, composed mainly of terpenes. The species of tree, the country, and differing methods of extraction cause it to vary considerably. In the United Kingdom, its place has been taken to a great extent by white spirit.

Acute toxic effects are fairly well known. It is an acute gastric irritant and has on rare occasions a specific acute inflammatory effect on the kidneys. Chronic effects are not believed to occur (Legge, 1931). Dermatitis from turpentine may be common (Pirilä, 1947) but depends on the method of extraction, the turpentine produced by destructive distillation of wood chips being the most aggressive (McCord, 1926).

Coal Tar Solvent Naphtha (B.R. $110^{\circ}$ to $160^{\circ} \mathrm{C}$.). - This is variously composed of higher aromatics (no benzene) or an aromatic-aliphatic hydrocarbon mixture. Apart from gassing effects, no acute poisoning has been recorded. No chronic systemic effects are known. The vapour is, however, irritant and sufficiently unpleasant to make it the subject of comment by men using it for the first time. Warning should be given that it is irritant but harmless.

\section{Other Solvents-Alcohols}

Methanol (methyl alcohol) (B.R. $64 \cdot 5^{\circ}$ to $65 \cdot 5^{\circ} \mathrm{C}$.). - This is well known as a poison, especially to the central nervous system. Optic atrophy is the best known effect, but several other cerebrospinal effects have been reported. Cases of poisoning have been confirmed due to inhalation of fumes from an industrial process. Skin absorption, sufficient in quantity to cause poisoning, has also been described (Browning, 1952).

Methylated SPIRIT.-This usually contains 5\% methanol as a denaturant and has no serious industrial hazard, although the danger of drinking it is well known.

IsOPROPANOL (isopropyl alcohol I.P.A.) (B.P. $82 \cdot 4^{\circ} \mathrm{C}$.). - This has no special industrial hazard.

Butanol (n. butyl alcohol) (B.R. $115^{\circ}$ to $118^{\circ} \mathrm{C}$.).This also has no special hazard. Its irritating vapour makes it unpopular with painters, and it is wise to warn them in advance before introducing it. It is stated to have caused severe conjunctivitis and keratitis (Krüger, 1932; Tabershaw, Fahy, and 
Skinner, 1944). Isobutanol and secondary butyl alcohol are occasionally used but are even less likely to cause harm than the normal isomer.

Chlorinated Hydrocarbons.-These have the advantage of not igniting at ordinary temperatures, as do almost all other paint solvents. They may, however, disintegrate at high temperatures. Spolyar, Harger, Keppler, and Bumsted (1951) described a case of probable phosgene poisoning, and Little (1955) showed how phosgene could be produced by some chlorinated solvents at temperatures above $500^{\circ} \mathrm{C}$. Cigarette smoking did not produce phosgene because the temperature did not reach that level. Most of the chlorinated solvents used have narcotic properties, and three are well-known anaestheticsethyl chloride; chloroform, little used today on account of occasional serious liver damage; and trichloroethylene, still used as a safe anaesthetic for operations of short duration. Others have this potential of anaesthesia, which under industrial conditions may cause gassing and must be guarded against.

Some of the group, tetrachlorethane especially, carbon tetrachloride, and chloroform are known chronic liver poisons. Willcox (1915) reported a group of fatal cases from tetrachlorethane in aircraft dope, and it is not now used in paint in the United Kingdom. Browning (1952) describes the other two as paint solvents but they are seldom used.

Methylene Dichloride $\left(\mathrm{CH}_{2} \mathrm{Cl}_{2}\right)$ (M.A.C. 500 p.p.m.).-This is used as a paint stripper and is safe provided adequate ventilation exists.

Trichloroethylene $\left(\mathrm{CH} \cdot \mathrm{Cl}_{3}\right)$ (M.A.C. 100 p.p.m.).-This is safe to use in paints in conditions of good ventilation. Used in medicine as a safe anaesthetic, if ventilation is poor it can cause unconsciousness. In lesser concentrations, symptoms such as faintness and lassitude may be experienced and may persist longer than similar symptoms from other solvents, such as hydrocarbons. Chronic poisoning, previously attributed to trichloroethylene (e.g., Stüber, 1931) are thought to be due to impurities produced by older methods of manufacture, particularly dichloroacetylene. Modern manufacture gives an almost pure product, and the various conditions have ceased to be reported in spite of a vast increase of usage in industry.

Perchloroethylene (tetrachlorethylene $\mathrm{CCl}_{2}$ : $\mathrm{CCl}_{2}$ ) (M.A.C. 100 p.p.m.) (B.R. $119^{\circ}$ to $121^{\circ} \mathrm{C}$.). This is regarded as even less likely to cause chronic poisoning than trichlorethylene.
1,1,1-TrichloRethaNe (methyl chloroform) $\left(\mathrm{C}\left(\mathrm{CH}_{3}\right) \mathrm{Cl}_{3}\right)$ (M.A.C. 500 p.p.m.). - This is the latest chlorinated solvent to come into the paint field. It appears to be remarkably safe.

\section{Ketones}

ACETONE $\left(\mathrm{CH}_{3} \cdot \mathrm{CO} \cdot \mathrm{CH}_{3}\right)$ (M.A.C. 500 p.p.m.).Apart from gassing and eye irritation, the only cases of poisoning reported have been of skin absorption in two young hospital patients whose extensive plaster-of-Paris casts had an acetone-based material applied, and whose exposure must have been very considerable.

Methyl Ethyl Ketone $\left(\mathrm{C}_{2} \mathrm{H}_{5} \cdot \mathrm{CO} \cdot \mathrm{CH}_{3}\right)$ (M.A.C. 200 p.p.m.).

M E T H Y L I S O B U T Y L K E T O N E $\left(\mathrm{CH}_{3} \cdot \mathrm{CO} \cdot \mathrm{CH}_{2} \cdot \mathrm{CH} \cdot\left(\mathrm{CH}_{3}\right)_{2}\right)$ (M.A.C. 200 p.p.m.).No poisoning is recorded with either of these, but M.I.B.K. has an irritating effect on the eyes and nose in very low concentration (below $0 \cdot 1 \%$ ).

Esters.-Methyl acetate, ethyl acetate, butyl acetate, amyl acetate, and ethyl lactate are all used in the paint industry in making cellulose lacquers. They are relatively harmless. Irritation of the eyes and nose may be noticed, a sweet cloying smell may be disliked: the usual symptoms and signs of gassing and the depressed functions of near-gassing will also be noticed in appropriate environmental conditions.

In general, the really troublesome materials have been benzene, tetrachlorethane, and, to a lesser extent, methanol. Though not noxious, alarm and discomfort are caused mainly by butanol, solvent naphtha, and M.I.B.K. Gassing can be caused by almost any solvent, its volatility being a guide to the extent of the danger.

Pigments.-Pigments used in paints in 1965 may be classified thus: (1) dyestuff-based; (2) earth pigments, such as ochres; and (3) inorganic pigments.

Generally, pigments are added to paint in considerable proportion by weight. Percentages of less than 5 are unlikely to be of interest in paint formulations.

Dyestuff-based Pigments.-These are complex organic materials of different types. Many are made by combining a dyestuff with a core to make it an insoluble lake, a soluble pigment having little use in paint as it would run or leach out or bleed through. The organic dyestuffs are all fairly innocuous industrially, their insoluble pigment equivalents much 
more so. So far as hazard to painters is concerned, this group can be ignored.

Earth Pigments.-These have the great merit of a long history; some indeed were used in the cave paintings of Altamira and Lascaux. They are not known to be hazardous.

\section{Inorganic Pigments}

LEAD. - Of all pigments, lead is well known in history as the outstanding toxic hazard in paints. Many forms of it have been used, the carbonate (white lead), oxides (litharge, red lead), sulphate, oxychloride (Turner's yellow), acetate (sugar of lead), borate, and chromates. Varying degrees of purity or of blending may take place, and this is particularly important among the lead chromes. These have colours varying from orange through yellows (lemon chrome) to greens. The paler, such as lemon chrome, may contain substantial quantities of white lead; greens are blended with Prussian blue.

Lead pigment must be treated with respect and, in spite of differing solubilities in water, the hazard of plumbism is always present and must be treated seriously. The hazard arises where lead dust is produced, as in paint spraying or rubbing down. Notwithstanding this danger, there is still a place for lead chromes in brush-applied paints, as they have exceptionally good covering power.

Although there is not statutory restriction on the use of lead in paints in the United Kingdom, the regulations restrict the use of 'lead paint', that is containing more than $5 \%$ 'soluble' lead, and prohibit its spraying. In 1961, the Ministry of Health and the Paintmakers' Association, representing fourfifths of the paint manufacturers in the United Kingdom, agreed that all paints containing $1 \%$ lead or more (the lead now being measured as metallic lead) should be labelled 'Unsuitable for use on children's toys or furniture or for interior decoration'. This figure agrees approximately with the British Standards Specification and the American Paediatric Association's recommendations and should greatly diminish the danger to children.

CADMIUM.-Cadmium pigments as used in paints are cadmium sulphide or cadmium sulphoselenides, with some barium sulphate present.

Although there have been cases of cadmium poisoning, the greatest number have been attributed to contamination of food by cadmium-plated containers and the inhalation of fumes in electroplating. These pigments are used in low concentrationsbelow $5 \%$ metallic cadmium in the liquid paint. Prodan (1932) thought that the dust was dangerous, but Deribiere (1943) and Princi (1947) both considered the pigments to be innocuous. Cotter and Cotter (1951) reported a case of poisoning from 'burning off' cadmium-containing paint and of cadmium clips.

Chromium.-Chromium pigments are used in several forms. The commonest are the lead chromes which are known to carry a greater lead than chromate hazard. No hazard has been brought to book from the use of lead chromes in industry, and only rarely has plumbism been debited to their use. The same applies to barium chromate. Lead chromes are not chemically altered by the paint vehicle, which might well have made them more easily absorbable.

Other pigments containing chromium are Guignet's green $\left(\mathrm{Cr}_{2} \mathrm{O}_{3} \cdot 2 \mathrm{H}_{2} \mathrm{O}\right)$, in which the chromium is trivalent, and chromium oxide $\left(\mathrm{Cr}_{2} \mathrm{O}_{3}\right)$. Neither of these appears to have caused trouble, although small quantities have been used in paint for many years.

Zinc chromate is the last and most controversial of the chromates. Apart from dermatitis, its toxic properties cannot be accurately assessed. It is a very useful rust inhibitor and has partially replaced red lead in metal primers. In primers and undercoats, zinc chromate is likely to be used in concentrations of the order of 2 to $5 \%$. It may be included in red oxide primers as well as bright yellow zinc chromate primers. The real problem here is the possibility of carcinoma of the bronchus. Many chromate cases have been reported from the United States of America (Machle and Gregorius, 1948) and from Germany (Lehmann, 1932; Gross and Alwens, 1938), almost exclusively in chromate manufacturing plants. In these, chromate ore, monochromates, bichromates, and chromic acid are all present. Gross and Alwens (1938) and Machle and Gregorius (1948) agreed that the alkaline monochromates were most likely to be the noxious agents, mainly sodium and potassium salts. Gross and Kölsch (1943) suggested zinc chromate dust as the most likely agent, since it is the more soluble salt. Trivalent chromium, present in the residue, has also been considered.

The picture is confused but the suspicion exists that zinc chromate carries this hazard, and precautions against inhaling spray dust from primers and undercoats should be enforced. No case has ever been associated with paints. The hazard is much less than that from smoking cigarettes, for which no precautions are enforceable. The situation is further complicated because few spray painters use or wear any protection, whether spray booths are provided or respirators.

Other inorganic pigments, including antimony (as antimony oxide), zinc, titanium, copper, manganese, 
and iron, are not known to be hazards to paint operators.

A recent enquiry arose over the use of prepainted steel girders, i.e., primed before erection. The hazards of welding or rivetting them include the possibility of metal fume fever, and this was discussed at a meeting of the Institute of Welding. Certain formulations were shown to be safe when used under conditions of reasonable ventilation. These formulae were based on zinc or zinc oxide.

Fungicides (Mildewcides), Herbicides, and Insecticides.-These ingredients are added to paints in the discharge of their nominal action, usually in small concentrations, for example, fungicides are added to paints for use in the tropics to inhibit the growth of mildews, which can speedily detach and destroy a paint film. Paint for ships' bottoms needs fungicidal, herbicidal, and antibarnacle properties. Attempts have been made also to incorporate insecticides in paint to kill flies and insects where these can be dangerous or particularly undesirable, such as in food stores. Not unexpectedly, the first materials considered were general protoplasmic poisons, but today the field has narrowed and more specific inhibitors are used.

Mercuric Oxide ( $\mathrm{HgO})$. - This was used in antifouling paints for ships' bottoms from about 1850 onwards. No case of poisoning has been reported from its use, not even in ship-breaking. The latter is explained by the slow leaching out of mercury by sea water, so that little or none remains finally.

Diggle (1955) painted rats' skins with antifouling paints containing different mercurials. When mercuric oxide was used, there was no evidence of absorption of mercury, since neither urine nor blood showed any rise above normal levels. When, however, phenyl mercuric derivatives were used, mercury was shown to be rapidly and fairly completely absorbed through the skin. Goldberg and Shapero (1957) tested groups of mice and guinea-pigs against paint containing phenyl mercuric derivatives by keeping them in cages painted with mercurial paints and by feeding experiments for six months. Urinary excretion rates of mercury were not raised to danger levels and post-mortem examinations did not show the animals to have been adversely affected; it was concluded that rooms painted thus were safe. The concentrations varied from emulsion paints with $0 \cdot 1$ to $0.65 \%$ phenol mercuric esters and oil paints with $1.2 \%$. This confirmed Cotter's (1947) conclusion that hazards were confined to the manufacturing stage.

Dimond and Stoddard (1955) estimated mercury evaporation from paints containing di(phenyl mercuric) dodecinyl succinate (D.P.M.D.S.) in greenhouses where they were investigating diseases of roses. They showed that mercury was released for several hours after drying in extremely small quantities.

Hirschman, Feingold, and Boylen (1963) described a case of acrodynia (pink disease) in a 6-year-old boy, who had been sleeping in a room painted with a mercury-containing emulsion paint. As he had helped his mother to paint the room, it is almost certain that he would have absorbed mercury through the skin or ingested it from the hands. Goldwater and Jacobs (1964) carried out tests by painting rooms with similar paints and found no significantly high amounts of mercury in the urine and blood of painters and others present. Furthermore, after 24 hours with no exceptional attempts at ventilation, the mercury concentration in the atmosphere decreased to an insignificant level.

In the case of organic mercurials, fortunately the aliphatic (alkyl) mercurials have not been used in paints; they would almost certainly present a serious hazard to painters in the sort of concentrations needed to be effective. The aryl mercurials, however (nearly always phenyl mercuric derivatives such as the acetate or propionate), have not been found to be dangerous.

The one case of acrodynia in a child was certainly not due to inhalation and may have been due to heavy exposure with paint contact. As Diggle (1955) showed, these mercurials in paint will penetrate the skin; in general, after absorption the aryl mercurials behave like inorganic mercury (Gage, 1964).

Emulsion paint containing aryl mercurial preservatives in low concentrations appears to be quite safe 24 hours after application, but probably not safe for young children to handle in the undried state (sensitivity to mercury, producing acrodynia, is peculiar to young children). Although low concentrations of mercury make it unlikely to cause harm, higher concentrations would need careful consideration. It should be noted that phenyl mercuric nitrate is used therapeutically in the treatment of fungal infections of human skin, as a biological preservative, in spermicidal jellies, and as a babies' diaper disinfectant. Sensitization dermatitis is known to occur with foot preparations containing phenyl mercuric nitrate.

Emulsion paints containing phenyl mercuric derivatives have some skin hazard to the painter, but no greater than that of paints in general.

Pentachlorphenol and Derivatives.-These materials have been used as wood preservatives for many years, baulks of wood being dipped into watery solu- 
tions, and as mildewcides in emulsion and tropical paints.

Menon (1958) reported nine deaths in 18 months in Sarawak, where local labour, mainly young Dyaks, was employed. A solution of 1.5 to $2 \%$ of pentachlorphenol or sodium pentachlorphenate was used. The men were soaked substantially most of the working day. Humidity was high and the temperature ranged from $70^{\circ}$ to $90^{\circ} \mathrm{F}$. The only features of the cases were hyperpyrexia, T. $101^{\circ}$ to $108^{\circ} \mathrm{F}$., and the rapid downward course lasting from nine to 25 hours. Menon states that, since providing protective clothing, no further case has occurred.

Gordon (1956) reported a group of nine cases with five deaths in Queensland on pineapple farms using $1 \%$ spray. Again, 30 hours to death was the longest course run.

L'Épée, Blanc, Lavignolle, Lazarini, and Fave (1963) reported three cases in France with one death: the other two both had rashes. Roberts (1963) in the United States of America reported a fatal case of aplastic anaemia in a man exposed to $3 \%$ pentachlorphenol and $1.5 \%$ tetrachlorphenol.

Campbell (1952) described a group of seven cases in Bristol, all of whom had used a domestic wood preservative, one only three times. Symptoms were of peripheral nephritis and of retro-bulbar neuritis. It is believed that a $5 \%$ solution was used. All recovered in three to six months.

It is clear that these two materials can be noxious at concentrations of $1 \%$. Gordon's cases were due to spray which gives optimum opportunity for inhalation as well as skin contamination but the cases of Menon, L'Épée et al., and Roberts all had massive skin exposure. Campbell's cases, in contrast, had hand and forearm exposure only and were in a temperate climate.

It is well known that pentachlorphenol and derivatives can be absorbed through the skin. This appears to be far more dangerous under hot conditions.

The safe concentration for fungicidal paints is still a matter for speculation. One manufacturer has used $0.5 \%$ sodium pentachlorphenate maximum for several years without apparent trouble. Skin protection and avoidance of prolonged contact is recommended.

Pentachlorphenol laurate appears to be considerably less noxious than pentachlorphenol or its sodium salt.

Tin.-A number of organic tin compounds were considered as possible fungicides in paints, but the Stalinon disaster in France caused considerable attention to be directed to possible serious toxic hazards. Stalinon itself was supposed to contain diethyl tin di-iodide, but Barnes and Stoner (1959) concluded that the neurological signs and deaths were the result of triethyl tin impurities. Today one compound, tributyl tin oxide (T.B.T.O.), is regarded as the best and safest choice. Its use in paints is in small concentrations up to about $0.5 \%$.

Other fungicides in use or likely to be used include copper sulphate, borates, calcium, zinc and aluminium stearates, tetramethylthiuram disulphide, and the arsenates of methyl copper and methyl silver. The last two will introduce a serious arsenical hazard, especially of arsine production; arsine has a M.A.C. of 1 p.p.m. and is noxious and even lethal at very low concentration; it is formed by chemical reduction of an arsenical salt or oxide. Of the others, there is no reason to suspect any special risk in the proportions likely to be used.

Hardeners.-Some of these are organic amines and are strongly alkaline and corrosive, as supplied to the painter in a two-pack system. In recent years the more noxious amines have been replaced more and more by 'Versamids' which are amides, blocked chemically to reduce this corrosiveness but not losing their amine property of paint hardening and drying

Rust Inhibitors.-These include red lead and zine chromate which have been discussed.

Anti-Oxidants.-These include hydroquinons, phenols and oximes. Concentrations in paints are small.

Plasticizers.-Dibutyl phthalate is widely used; adipic acid and sebacic acid, and their esters, and polyester resins, including maleic residues, are used occasionally; sulphonamides, T.O.C.P. (Triortho cresyl phosphate or tritolyl phosphate) as well as chlorinated hydrocarbons such as chlorinated diphenyls are also used. The risk of T.O.C.P. has been discussed; chlorinated diphenyls are known liver poisons but are not present undiluted.

Industrial dermatitis occurs among painters and other employees (Pirilä, 1947) in the application of paints, as in most other industries. It is most often caused by the traditional, convenient, and harmful custom of cleaning the hands with paint thinners. Usually a few vesicles occur on the front of the wrists and in the interdigital clefts at first. Both hands are affected as a rule. Vesicles are sometimes seen higher up the forearm and in the antecubital fossa. In these cases there may be other factors, such as abrasion by rough rolled-up overall cuffs. When 
these higher lesions are seen with no rash on the hands and wrists it may be that short protective gloves have been worn. Other personal factors affecting the outbreak of symptoms may be age, long exposure to solvents breaking down the natural resistance or exhausting the natural recuperative powers of the skin (Schwartz, Tulipan, and Birmingham, 1957), and acute illness or general debility from chronic disease. These irritative cases may become chronically eczematized if exposure continues for long. Cases seen early and treated, usually with temporary removal from exposure, clear up within weeks and should not recur, if working habits have been corrected. Eczematized cases may be resistant to treatment.

In contrast, and much less commonly, sensitization dermatitis may occur. Usually the face and neck are involved and there are other well-known clinical differences. A great many possible sensitizing agents are used in paints, many resins, most solvents, a few pigments, and other minor ingredients being among them. Sensitization dermatitis is usually seen with a material used in a particular way. An example of this is in the epoxide resins, which have been shown by Calnan (1958) to be sensitizing agents. Nearly all cases reported have been in the processing of plastics, an irritation eczema also being produced by some amine hardeners. In paints, however, few cases of dermatitis have been reported in spite of extensive use over a number of years.

The conclusion to be drawn from this is that, since the incidence of dermatitis varies so much with methods of use, there are many ways of using most materials safely. Prevention should be effective, since a sensitized worker may have to leave his occupation permanently. Safe usage of most materials is feasible in any well-organized and welldisciplined paint shop; unfortunately, many employers appear to exert little control over their operators, and precautions are minimal.

The control of industrial dermatitis is well known. Good industrial hygiene, training and continued supervision, especially in painting, and preventing hand-washing with solvents can eliminate irritative dermatitis. Occurrence of sensitization is reduced in this way, but specific measures can only be used after the allergen has been identified out of the many possibilities. Assessment of all the factors in the situation with the management will govern which of several courses to take-removal of the allergen, mechanization of methods of application or the provision of protective equipment for painters.

\section{REFERENCES}

American Conference of Government Industrial Hygienists (1964). Arch. environm. Hlth, 9, 545 .
Barnes, J. M., and Stoner, H. B. (1959). Pharmacol. Rev., 11, 211.

Bosshard, R. (1959). Z. Unfallmed. Berufskr., 52, 218.

Browning, E. (1952). Toxicity of Industrial Organic Solvents. Industr. Health Research Board Rep. No. 80 (rev. ed.). London.

Calnan, C. D. (1958). Trans. St John's Hosp. Derm. Soc. (London), No. 40 , p. 12.

Campbell, A. M. G. (1952). Brit. med. J., 2, 415.

Cotter, L. H. (1947). Occup. Med., 4, 305.

- and Cotter, B. H. (1951). Arch. industr. Hyg., 3, 495.

Deribiere, M. (1943). Rev. tech. Industr. Cuir., 34, 69.

Diggle, W. M. (1955). Internal communication, Imperial Chemical Industries Limited. HR/74.

Dimond, A. E., and Stoddard, E. M. (1955). Conn. agric. exp. Sta. Bull., 595.

Duncan, B., Scheel, L. D., Fairchild, E. J., Killens, R., and Graham, S. (1962). Amer. industr. Hyg. Ass. J., 23, 447.

Ehrlicher, H., and Pilz, W. (1956). Arbeitsschutz, p. 276

Friebel, H., and Lüchtrath, H. (1955). Naunyn-Schmiedeberg's Arch. exp. Path. Pharmak., 227, 93.

Fuchs, S., and Valade, P. (1951). Arch. Mal. prof., 12, 191.

Gage, J. C. (1964). Brit. J. industr. Med., 21, 197.

Goldberg, A. A., and Shapero, M. (1957). J. Pharm. Pharmacol., 9, 469.

Goldwater, J. L., and Jacobs, M. B. (1964). Nov. 9. Unpublished Report.

Gordon, D. (1956). Med. J. Aust., 2, 485.

Gross, E., and Alwens, W. (1938). Bericht. VIII Int. Kongress Unfallmedizin and Berufskrankheiten, Frankfurt, 1938. (Thieme, Stuttgart.)

-, and Kölsch, F. (1943). Arch. Gewerbepath. Gewerbehyg., 12, 164.

Grumske, F. (1949). Dtsch. med. Wschr., 74, 1081.

Hendry, J. A., Horner, R. F., Rose, F. L., and Walpole, A. L. (1951). Brit. J. Pharmacol., 6, 235.

Henschler, D., Assmann, W., and Meyer, K. O. (1962). Arch. Toxikol., $19,364$.

Hine, C. H., Kodama, J. K., Anderson, H. H., Simonson, D. W., and Wellington, J. S. (1958). Arch. industr. Hlth, 17, 129.

Hirschman, S. Z., Feingold, M., and Boylen, G. (1963). New Engl. J. Med., 269, 889.

Klavis, G., and Schulz, L. C. (1959). Arch. Toxicol., 17, 338.

Kodama, J. K., Guzman, R. J., Dunlap, M. K., Loquvam, G. S., Lima, R., and Hine, C. H. (1961). Arch. environm. Hlth, 2, 50.

Krüger, E. (1932). Arch. Gewerbepath. Gewerbehyg., 3, 798.

Lawrence, J. R. (1960). Polyester Resins. Reinhold Publ. Corp., New York.

Legge, T. (1931). Committee for Compensation of Industrial Diseases.

Lehmann, K. B. (1932). Zbl. Gewerbehyg., n.s. 9, 168.

L'Épée, P., Blanc, M., Lavignolle, A., Lazarini, H. J., and Fave, M. (1963). Arch. Mal. Prof., 24, 310.

Little, J. (1955). Brit. J. industr. Med., 12, 304.

Lomonova, G. V. (1962). Gig. Tru. prof. Zabol., 6, no. 6, p. 54.

Lorz, H. (1950). Dtsch. med. Wschr., 75, 1087.

Machle, W., and Gregorius, F. (1948). Publ. Hlth Rep. (Wash.), 63, 1114 .

Maglio, M. M. (1948). Chemist-Analyst, 37, 4.

Malten, K. E., and Zielhuis, R. L. (1964). Industrial Toxicology and Dermatology in the Production and Processing of Plastics. Elsevier, Amsterdam.

Massmann, W. (1956). Brit. J. industr. Med., 13, 51.

McCord, C. P. (1926). J. Amer. med. Ass., 86, 1979.

Menon, J. A. (1958). Brit. med. J., 1, 1156.

Munn, A. (1960). Trans. Ass. industr. med. Offrs., 9, 134.

Non-Convertible Coatings (1961). Oil and Colour Chemists' Association.

Pirilä, V. (1947). On Occupational Diseases of the Skin Among Paint Factory Workers, Painters, Polishers and Varnishers in Finland. Acta derm.-vener., 27, Suppl. 16, Helsinki.

Princi, F. (1947). J. industr. Hyg., 29, 315.

Pokrovski, V. A. (1961). Gig. tr. prof. Zab., 5, no. 5, p. 3.

Prodan, L. (1932). Ibid., 14, 132.

Roberts, J. H. (1963). Sth med. J. (Bgham., Ala.), 56, 632.

Schürmann, D. (1955). Dtsch. med. Wrschr., 80, 1661.

Schwartz, L., Tulipan, L., and Birmingham, D. J. (1957). Occupational Diseases of the Skin. 3rd ed. Lea and Febiger, Philadelphia.

Skeist, I. (1958). Epoxy Resins. Reinhold, New York. 
Spencer, H. C., Irish, D. D., Adams, E. M., and Rowe, V. K. (1942). J. industr. Hyg., 24, 295.

Spolyar, L. W., Harger, R. N., Keppler, J. F., and Bumsted, H. E. (1951). Arch. industr. Hyg., 4, 156.

Stüber, K. (1931). Arch. Gewerbepath. Gewerbehyg., 2, 398.

Strayer, S. C. (1959). Arch. industr. Hlth, 19, 351.

Swensson, Å., Holmquist, C. E., and Lundgren, K. D. (1955). Brit. $J$. industr. Med., 12, 50.

Tabershaw, I. R., Fahy, J. P., and Skinner, J. B. (1944). J. industr. Hyg., 26, 328.

Treon, J. F., Sigmon, H., Wright, H., and Kitzmiller, K. V. (1949) Ibid., 31, 317.

von Oettingen, W. F., Neal, P. A., Donahue, D. D., Svirbely, J. L. Baernstein, H. D., Monaco, A. R., Valder, P. J., and Mitchell, J. L. (1942). The Toxicity and Potential Dangers of Toluene, with special reference to its maximal permissible concentration. U.S. Publ. Health Bull., No. 279.

Walpole, A. L., and Williams, M. H. C. (1959). J. Oil Colour Chemists' Ass., 42, 694.

Willcox, W. H. (1915). Trans. med. Soc. Lond., 38, 129.

Wolf, M. A., Rowe, V. K., McCollister, D. D., Hollingsworth, R. L., and Oyen, F. (1956). Arch. industr. Hlth, 14, 387.

Zapp, J. A. (1957). Ibid., 15, 324.

Zielhuis, R. L. (1961). (Cited by Malten and Zielhuis.) 